\title{
Elevated von Willebrand Factor Antigen Is an Early Plasma Predictor of Acute Lung Injury in Nonpulmonary Sepsis Syndrome
}

\author{
David B. Rubin, Jeanine P. Wiener-Kronish, John F. Murray, David R. Green, Joan Turner, John M. Luce, \\ A. Bruce Montgomery, James D. Marks, and Michael A. Matthay \\ Departments of Medicine and Anesthesia, University of California Medical Center, San Francisco General Hospital Medical Center, \\ San Francisco, California 94143; and Departments of Medicine and Therapeutic Radiology, Rush Presbyterian-St. Luke's \\ Medical Center, Chicago, Illinois 60612; and Northwestern University Medical School, Chicago, Illinois 60611
}

\begin{abstract}
In this prospective study of $\mathbf{4 5}$ patients, we tested the hypothesis that markedly elevated levels of plasma von Willebrand antigen (vWf-Ag) a marker of endothelial cell injury, might predict the development of acute lung injury in patients with nonpulmonary sepsis syndrome. Acute lung injury was quantified on a four-point scoring system. At the time of entry into the study, none of the 45 patients had evidence of lung injury. Subsequently, 15 patients developed lung injury and 30 patients did not develop lung injury. The mean plasma vWf-Ag level was markedly elevated in the 15 patients who developed lung injury compared with the 30 patients who did not develop lung injury (588 \pm 204 vs. $338 \pm 196$, percentage of control, $P$ $<0.01$ ). Furthermore, a plasma vWf-Ag level $\geq 450$ was $87 \%$ sensitive and $77 \%$ specific for predicting the development of acute lung injury in the setting of nonpulmonary sepsis. In addition, the combination of a plasma vWf- $\mathrm{Ag}>450$ and nonpulmonary organ failure at the time of entry into the study had a positive predictive value of $80 \%$ for acute lung injury. Also, a plasma vWf-Ag level $>\mathbf{4 5 0}$ had a positive predictive value of $80 \%$ for identifying nonsurvivors. Thus, in patients with nonpulmonary sepsis, an elevated level of plasma vWf-Ag is a useful, early biochemical marker of endothelial injury and it has both predictive and prognostic value. (J. Clin. Invest. 1990. 86:474-480.) Key words: endothelial cells • acute lung injury • von Willebrand antigen level • sepsis • adult respiratory distress syndrome $\bullet$ shock
\end{abstract}

\section{Introduction}

A number of in vitro and in vivo studies have reported that endotoxemia and bacteremia cause injury to endothelial cells (1-4). In addition, several investigators have reported that von Willebrand factor antigen ( $\mathrm{vWf}-\mathrm{Ag})^{1}$ is primarily a product of endothelial cells and is also a sensitive marker of endothelial cell injury (5-8). Therefore, in this study we have examined the hypothesis that elevated levels of plasma vWf-Ag would

Address reprint requests to Dr. Matthay, Cardiovascular Research Institute, Box 0130, University of California, San Francisco, CA 94143. Received for publication 9 January 1990.

1. Abbreviations used in this paper: PEEP, positive end-expiratory pressure; vWf-Ag, von Willebrand factor antigen.

J. Clin. Invest.

(c) The American Society for Clinical Investigation, Inc.

0021-9738/90/08/0474/07 $\$ 2.00$

Volume 86, August 1990, 474-480 identify which patients with sepsis syndrome were likely to develop acute lung injury.

Markedly elevated levels of plasma vWf-Ag have been reported in adults and children with acute respiratory failure $(9$, 10). However, no studies have examined the possible predictive value of an endothelial cell marker in patients with sepsis syndrome before the onset of acute lung injury. In a preliminary study of several plasma markers of endothelial cell injury, we found that the levels of angiotensin converting enzyme and lactic dehydrogenase isoenzymes did not predict or correlate with the development of acute lung injury in sepsis (11). However, we found, as previously reported (9), that elevated levels of plasma vWf-Ag were present in patients with established acute respiratory failure. We also found that elevated levels of plasma vWf-Ag ( $>450$, percentage of control) were present in six patients with nonpulmonary sepsis who did not have respiratory failure, but then subsequently progressed to develop acute lung injury.

Therefore, we studied a larger number of patients prospectively to define the sensitivity and specificity of $\mathrm{vWf}-\mathrm{Ag}$ as a predictive plasma marker for the development of acute lung injury in patients with nonpulmonary sepsis. In addition, we examined several commonly measured clinical variables including systolic and diastolic blood pressure, arterial $\mathrm{pH}$, as well as circulating leukocytes and platelets to determine their predictive value in identifying which patients with sepsis syndrome would progress to develop acute lung injury. We also analyzed the impact of renal, hepatic, central nervous system, and hematologic organ failure that was present at the time sepsis syndrome was diagnosed on the development of acute lung injury as well as on the final outcome.

\section{Methods}

Patient selection. The entry criteria for patients with suspected sepsis syndrome were the presence of a temperature $\geq 38.3$ or $<35.0^{\circ} \mathrm{C}$, and a systolic blood pressure $\leq 100 \mathrm{~mm} \mathrm{Hg}$ or a drop of $20 \mathrm{~mm} \mathrm{Hg}$ or more in the systolic blood pressure from the base-line value that could not be attributed to dehydration or cardiac failure. A total of 62 patients were recruited into the study. Subsequently, seven patients were subsequently excluded because review of their data indicated their hypotension was related to hypovolemia or cardiac failure, or there was no evidence to support sepsis as the etiology of their hypotension; 10 patients were excluded because they already had evidence of lung injury (score $>0$ as explained below) when first seen. Thus, a total of 45 patients were included in the final results of the study. All patients were cared for either in the intensive care unit at the University of California Medical Center $(n=21)$ or in the medical or surgical intensive care unit at San Francisco General Hospital $(n=24)$. The patients were recruited from two sources: from already hospitalized patients whose onset of presumed septic shock was within $4 \mathrm{~h}$ of entry into the study, or from patients whose time of onset of septic shock was less 
certain because they were admitted to the intensive care unit from the emergency department or from the operating room.

Of the 45 patients included in the final analysis, 16 had no prior history of major medical or surgical diseases. Of the remaining 29 patients, the underlying medical disorders were malignancy $(n=10)$, cirrhosis $(n=6)$, renal disease $(n=5)$, cardiac disease $(n=3)$, intravenous drug abuse $(n=2)$, and miscellaneous disorders $(n=3)$. A total of four patients received corticosteroids during their hospitalization.

Assessment of lung injury. The assessment of acute lung injury was based on a composite four-point scoring system that included evaluation of the chest radiograph and arterial oxygenation, as well as the respiratory system compliance and level of positive end-expiratory pressure (PEEP) in patients who were intubated and mechanically ventilated. This scoring system was similar to the one that we have used in the past (12), and was recently described in detail (13).

The details of the lung injury scoring system are provided in Table I. To score the chest radiograph, each lung was divided into an upper and lower zone by an imaginary horizontal line originating from the hilum. Each chest radiograph was then evaluated by an observer who was unaware of the patient's clinical or laboratory status. For evaluating oxygenation, we previously used the arterial to alveolar partial pressure ratio $\left(\mathrm{PaO}_{2} / \mathrm{PAO}_{2}\right)(12,14)$. However, we now prefer using the single $\mathrm{PaO}_{2} / \mathrm{FiO}_{2}$ ratio because it is more easily calculated and provides

Table I. Components of the Lung Injury Score

\begin{tabular}{|c|c|c|}
\hline & Value & \\
\hline \multicolumn{3}{|l|}{ Chest roentgenogram score } \\
\hline No alveolar consolidation & & 0 \\
\hline Alveolar consolidation in one quadrant & & 1 \\
\hline Alveolar consolidation in two quadrants & & 2 \\
\hline Alveolar consolidation in three quadrants & & 3 \\
\hline Alveolar consolidation in all four quadrants & & 4 \\
\hline \multicolumn{3}{|l|}{ Hypoxemia score } \\
\hline $\mathrm{PaO}_{2} / \mathrm{FiO}_{2}$ & $\geq 300$ & 0 \\
\hline $\mathrm{PaO}_{2} / \mathrm{FiO}_{2}$ & $225-299$ & 1 \\
\hline $\mathrm{PaO}_{2} / \mathrm{FiO}_{2}$ & $175-224$ & 2 \\
\hline $\mathrm{PaO}_{2} / \mathrm{FiO}_{2}$ & $100-174$ & 3 \\
\hline $\mathrm{PaO}_{2} / \mathrm{FiO}_{2}$ & $<100$ & 4 \\
\hline \multicolumn{3}{|l|}{$\begin{array}{l}\text { Respiratory system compliance score when } \\
\quad \text { ventilated }\left(\mathrm{ml} / \mathrm{cm} \mathrm{H}_{2} \mathrm{O}\right)\end{array}$} \\
\hline Compliance & $\geq 80$ & 0 \\
\hline Compliance & $60-79$ & 1 \\
\hline Compliance & $40-59$ & 2 \\
\hline Compliance & $20-39$ & 3 \\
\hline Compliance & $\leq 19$ & 4 \\
\hline \multicolumn{3}{|l|}{ PEEP score when ventilated $\left(\mathrm{cm}_{2} \mathrm{O}\right)$} \\
\hline PEEP & $\leq 5$ & 0 \\
\hline PEEP & $6-8$ & 1 \\
\hline PEEP & $9-11$ & 2 \\
\hline PEEP & $12-14$ & 3 \\
\hline \multirow[t]{2}{*}{ PEEP } & $\geq 15$ & 4 \\
\hline & Score & \\
\hline No lung injury & 0 & \\
\hline Mild-to-moderate lung injury & $0.1-2.5$ & \\
\hline Severe lung injury (ARDS) & $>2.5$ & \\
\hline
\end{tabular}

The final value is obtained by dividing the aggregate sum by the number of components that were used. Abbreviation: ARDS, adult respiratory distress syndrome. a similar evaluation of oxygenation (13). The respiratory system compliance and PEEP components were included in all patients who were mechanically ventilated.

To quantify the extent of acute lung injury, we averaged separately the gas exchange, radiographic, respiratory system compliance, and PEEP values. We totaled all points in each category and divided by the total number of categories. The maximum number of points assigned could be 16 . This score would be divided by 4 which would then yield a maximum score of 4 . On the basis of these scores, we classify the extent of lung injury into one of three categories: no lung injury, 0 ; mild to moderate lung injury, 0.1-2.5; severe lung injury, > 2.5 (Table I).

To determine the development of lung injury in our patients, all of whom had a lung injury score of 0 at the time of entry into the study, each patient had a lung injury score calculated once every $24 \mathrm{~h}$ for a total of $72 \mathrm{~h}$. The maximum score recorded during that time period was used to define the extent of acute lung injury.

Collection of blood and assays. Samples of venous or arterial blood were obtained in heparinized (dry) glass tubes. The tubes were centrifuged at $4^{\circ} \mathrm{C}$ at $3,000 \mathrm{~g}$ for $10 \mathrm{~min}$ within $30 \mathrm{~min}$ of collection. The plasma was then stored at $-70^{\circ} \mathrm{C}$. The specimens were sent in dry ice to Chicago for the vWf-Ag assays. Plasma vWf-Ag was quantified by gel rocket immunoelectrophoresis according to published methods $(15,16)$. Because the vWf-Ag levels in patient samples often exceeded control values by as much as 15 -fold, the samples were repeatedly diluted until rocket peaks fell in the midzone of the standard curve. The assays were done without any knowledge of the patient's clinical data. Reproducibility was tested by analyzing paired specimens; the results, expressed as percentage of control, were 760/784, 275/296, $448 / 424,307 / 330,480 / 452,424 / 453,300 / 400,159 / 180,700 / 672$, and 401/448. The mean \pm standard deviation of the 10 paired samples was $427 \pm 186 / 443 \pm 175$. The standard error of the mean for the daily variation was $3 \%$, and the standard error of the mean within an assay was $2 \%$.

Patient classification and collection of clinical data. All patients who met criteria for nonpulmonary sepsis syndrome and who had a lung injury score of 0 at the time of entry into the study were classified as group I if they did not develop lung injury (score remained 0 ) or group II if they developed lung injury (score $>0$ ) during the first $72 \mathrm{~h}$ after entry into the study.

Blood for routine bacterial culture as well as specimens for culture of any suspected source of infection were obtained from all patients. The patient's clinical respiratory status was evaluated at the time of admission to the study along with vital signs, physical examination findings, chest radiographic abnormalities, arterial blood gas values, laboratory data, and when available, respiratory system compliance, ventilator variables, and systemic and pulmonary hemodynamics.

The presence or absence of nonpulmonary organ failure was determined by the following criteria: renal failure was defined as a serum creatinine $>2.0 \mathrm{mg} / \mathrm{dl}$; hepatic failure was defined as a serum total bilirubin $>2.0 \mathrm{mg} / \mathrm{dl}$ in association with a prothrombin time that was $3 \mathrm{~s}$ or more greater than control; hematologic failure was defined as a platelet count $<75,000 / \mathrm{mm}^{3}$ or a total white blood cell count $<1,000$ cells $/ \mathrm{mm}^{3}$ or evidence of disseminated intravascular coagulation; neurologic failure was defined as obtundation (not attributable to sedation) or the presence of a primary central nervous system abnormality (seizures, recent cerebrovascular accident, or head trauma). The patient's history was reviewed to determine the presence or absence of chronic diseases that contributed to nonpulmonary organ failure at the time of entry into the study. Clinical data were recorded every $24 \mathrm{~h}$ for a total of $72 \mathrm{~h}$. Also, the patient's clinical outcome (death or discharge) was documented.

Statistics. All data are presented as mean \pm standard deviation. The differences in plasma vWf-Ag levels, $\mathrm{pH}, \mathrm{PaO}_{2}, \mathrm{PaCO}_{2}$, systolic blood pressure, diastolic blood pressure, white blood cell count, organ failure, and mortality between groups I and II were analyzed by an unpaired Student's $t$ test. $\chi^{2}$ analysis with Yates correction was also used to test for a significant predictive value of a plasma vWf-Ag level $>\mathbf{4 5 0}$ (percentage of control) for identifying which patients were destined to 


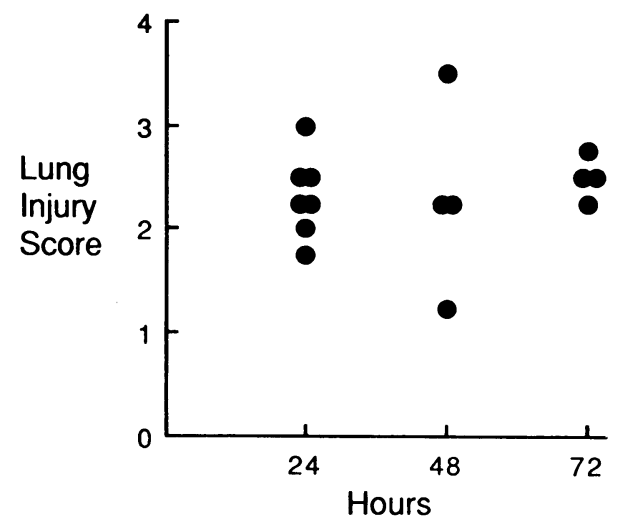

Figure 1. Individual points represent the maximum lung injury for each of the 15 patients in group II plotted against time $(24,48$, or 72 h) when maximum lung injury occurred. The lung injury score is described Methods and in Table I. All these 15 patients had a lung injury score of zero at the time they were entered into the study with the diagnosis of nonpulmonary sepsis syndrome.

develop lung injury as well as which patients were not likely to survive. We accepted $P<0.05$ as indicating statistical significance (17). Standard formulas were used to calculate sensitivity, specificity, as well as the positive and negative predictive value of plasma $\mathrm{vWf}-\mathrm{Ag}$ and the presence or absence of nonpulmonary organ failure at the time of diagnosis (17).

\section{Results}

A total of 45 patients were studied who met the criteria for sepsis syndrome and had no evidence of lung injury at the time of entry into the study. Of these 45 patients, 30 did not develop lung injury (group I), and 15 patients did develop lung injury, all of whom had bilateral infiltrates on the chest radiograph (group II). The majority of group II patients reached their maximum lung injury score within $48 \mathrm{~h}$ but in four patients the maximal injury occurred at $72 \mathrm{~h}$ (Fig. 1).

At the time of entry into the study, the mean systolic and diastolic blood pressure was approximately $10 \mathrm{~mm} \mathrm{Hg}$ lower in the group II patients compared to the group I patients (Table II). This difference reached statistical significance for the diastolic blood pressure, although there was considerable overlap in the individual data values. The mean $\mathrm{pH}$ was also significantly lower in the group II patients although again there was considerable overlap (Table II). There was no difference in the levels of circulating white blood cells at the time of entry into the study (Table II). The mean platelet counts were also similar between the two groups.
Review of the patient's medical history indicated that the incidence of chronic diseases that may have contributed to nonpulmonary organ failure was similar in both groups $(23 \%$, group I; $28 \%$, group II). However, by the time of entry into the study, the overall incidence of nonpulmonary organ failure was $93 \%$ in group II compared with $50 \%$ in group I patients $(P$ $<0.05$ ) (Table III). Furthermore, mortality was significantly higher for group II patients (93\%) compared with group I patients $(30 \%)(P<0.05)$. In fact, only one patient survived in group II and this was the only group II patient without organ failure at the time of entry into the study.

The organisms responsible for the sepsis syndrome, the anatomic source of sepsis, and the presence or absence of a positive blood culture were similar in the two groups (Tables IV and V). A positive blood culture was found in $50 \%$ of group I patients and $53 \%$ of the group II patients. Gram-negative organisms were the primary cause of sepsis in $77 \%$ of group I patients and in $73 \%$ of group II patients. Escherichia coli was the most common (40\%) cause of sepsis syndrome overall.

The mean plasma level of vWf-Ag for the 15 patients in group II who developed lung injury was $588 \pm 204$ (percentage of control), a value nearly twice as high as the mean plasma vWf-Ag level of $338 \pm 196(P<0.01)$ for the 30 patients in group I who did not develop lung injury. The individual data for each of the patients in groups I and II are shown in Fig. 2. Using a plasma vWf-Ag $\geq 450$ as a cutoff, the test was $87 \%$ sensitive and $77 \%$ specific for the development of acute lung injury $\left(P<0.0005, \chi^{2}\right)$ (Table VI). The positive predictive value for lung injury of a plasma vWf- $\mathrm{Ag}>450$ was $65 \%$ and the negative predictive value was $92 \%$. We also tested the effect of combining both a plasma vWf-Ag $>450$ and the presence of one nonpulmonary organ failure at the time of entry into the study for predicting lung injury. With this approach, the positive predictive value increased to $80 \%$, the sensitivity declined to $80 \%$, and the specificity increased to $87 \%$.

We also tested the possible value of an elevated plasma vWf-Ag level for identifying patients who were not likely to survive. Using a plasma vWf- $\mathrm{Ag}>450$ as a cutoff, the test was significantly predictive of mortality $\left(P<0.005, \chi^{2}\right)$ with a sensitivity of $70 \%$, specificity of $80 \%$, and a positive predictive value of $80 \%$.

\section{Discussion}

The primary purpose of this study was to determine the potential value of elevated levels of vWf-Ag in the plasma for predicting which patients with sepsis syndrome would progress to develop acute lung injury. A secondary goal was to learn more about the relationship of nonpulmonary organ failure at

Table II. Comparisons of Blood Pressure, Arterial pH, and White Blood Cell Counts at Time of Entry into the Study

\begin{tabular}{|c|c|c|c|c|c|}
\hline & \multirow[b]{2}{*}{ Patients } & \multicolumn{2}{|c|}{ Blood pressure } & \multirow[b]{2}{*}{ Arterial pH } & \multirow[b]{2}{*}{ White blood cells } \\
\hline & & Systolic & Diastolic & & \\
\hline & $n$ & \multicolumn{2}{|c|}{$\mathrm{mm} \mathrm{Hg}$} & & cells $/ \mathrm{mm}^{3}$ \\
\hline Group I (no progression) & 30 & $92 \pm 17$ & $52 \pm 12$ & $7.43 \pm 0.08$ & $14,479 \pm 9,252$ \\
\hline Group II (progression) & 15 & $84 \pm 13$ & $43 \pm 13^{*}$ & $7.35 \pm 0.11^{*}$ & $13,164 \pm 11,309$ \\
\hline
\end{tabular}

Data shown as Mean \pm SD. ${ }^{*} P<0.05$. 
Table III. Frequency and Distribution of Nonpulmonary Organ Failure at the Time of Entry into the Study

for Nonpulmonary Sepsis Syndrome

\begin{tabular}{lcccccr}
\hline & $\begin{array}{c}\text { Patients with } \\
\text { failure of at } \\
\text { least one }\end{array}$ & & \multicolumn{3}{c}{$\begin{array}{c}\text { Distribution of organ failure } \\
\text { at time of entry into study }\end{array}$} \\
\cline { 5 - 6 } Classification & $\begin{array}{c}\text { nonpulmonary } \\
\text { organ }\end{array}$ & Renal & Hepatic & Hematologic & CNS \\
\hline Group I $(n=30)$ & $15(50)$ & 8 & 3 & 4 & 11 \\
Group II $(n=15)$ & $14(93)^{*}$ & 7 & 6 & 8 & 8
\end{tabular}

Abbreviation: CNS, central nervous system.

${ }^{*} P<0.05$ comparing the percent with at least one nonpulmonary organ failure in group II compared with group I.

the time sepsis syndrome is diagnosed to the development of lung injury and mortality.

We chose to limit this study to patients with sepsis for a number of reasons. First, they represent a relatively homoge-

Table IV. Microbiology and Anatomic Source of Sepsis in Group I Patients

\begin{tabular}{|c|c|c|c|}
\hline No. & $\begin{array}{l}\text { Anatomic origin } \\
\text { of sepsis }\end{array}$ & Causative organism(s) & $\begin{array}{c}\text { Positive } \\
\text { blood } \\
\text { culture }\end{array}$ \\
\hline 1 & UTI & Enterobacter & - \\
\hline 2 & Biliary & E. coli & - \\
\hline 3 & Cellulitis & Streptococcus & + \\
\hline 4 & Fasciitis & Clostridia, Pseudomonas & - \\
\hline 5 & Biliary & Enterobacter & + \\
\hline 6 & UTI & E. coli & + \\
\hline 7 & UTI & E. coli & + \\
\hline 8 & UTI & E. coli & - \\
\hline 9 & UTI & Pseudomonas & - \\
\hline 10 & Septic arthritis & E. coli & - \\
\hline 11 & Peritoneal & Multiple enteric organisms & - \\
\hline 12 & UTI & E. coli & - \\
\hline 13 & Biliary & Aeromonas & + \\
\hline 14 & Peritoneum & Candida & + \\
\hline 15 & UTI & E. coli & - \\
\hline 16 & Peritoneum & Multiple enteric organisms & - \\
\hline 17 & Peritoneum & E. coli & + \\
\hline 18 & Peritoneum & Streptococcus & + \\
\hline 19 & Cellulitis & Streptococcus & - \\
\hline 20 & UTI & Candida & - \\
\hline 21 & UTI & E. coli & + \\
\hline 22 & Peritoneum & Bacteroides & + \\
\hline 23 & Biliary & Bacteroides, E. coli & - \\
\hline 24 & Endocarditis & Staphylococcus aureus & + \\
\hline 25 & Peritoneum & Klebsiella & + \\
\hline 26 & Peritoneum & E. coli & + \\
\hline 27 & Endocarditis & Staphylococcus aureus & + \\
\hline 28 & Biliary/Perit & E. coli, Clostridia perfringens & - \\
\hline 29 & Peritoneum & Multiple enteric organisms & - \\
\hline 30 & UTI & E. coli & + \\
\hline
\end{tabular}

Abbreviation: UTI, urinary tract infection.
Table V. Microbiology and Anatomic Source of Sepsis in Group II Patients

\begin{tabular}{rllr}
\hline No. & $\begin{array}{c}\text { Anatomic origin } \\
\text { of sepsis }\end{array}$ & \multicolumn{1}{c}{ Causative organism(s) } & $\begin{array}{r}\text { Positive } \\
\text { blood } \\
\text { culture }\end{array}$ \\
\hline 1 & Peritoneum & Bacteroides & + \\
2 & Cellulitis & Pseudomonas & - \\
3 & Peritoneum & Mucormycosis & - \\
4 & Fasciitis & Staphylococcus aureus & + \\
5 & UTI & M. Morganii & - \\
6 & UTI & E. coli & + \\
7 & UTI & E. coli & + \\
8 & Peritoneum & E. coli & + \\
9 & Peritoneum & Streptococcus pneumoniae & + \\
10 & Peritoneum & Salmonella & - \\
11 & Osteomyelitis & Pseudomonas & - \\
12 & UTI & E. coli & - \\
13 & Cellulitis/Biliary & Staphylococcus aureus/Klebsiella & + \\
14 & Peritoneum & E. coli & + \\
15 & Peritoneum & E. coli & - \\
& & &
\end{tabular}

Abbreviation: UTI, urinary tract infection.

nous group of patients with a high risk of developing acute lung injury $(13,18-20)$. Secondly, we have developed a wellcoordinated system at two hospitals for identifying patients with sepsis syndrome early in their clinical course (12). Thirdly, data from studies in animals and in humans has indicated that endothelial injury occurs early in endotoxemia and bacteremia $(3,4,21)$, and thus there is an experimentally based rationale for the hypothesis that elevated levels of $\mathrm{vWf}-\mathrm{Ag}$ in the plasma might be an early plasma marker of impending acute lung injury. Fourthly, our pilot clinical project in a few patients provided encouraging results in that a plasma level of vWf-Ag above 450 might be predictive of lung injury in patients with sepsis syndrome (11).

In addition, we decided to concentrate on patients who did not have lung injury at the time of enrollment because it has

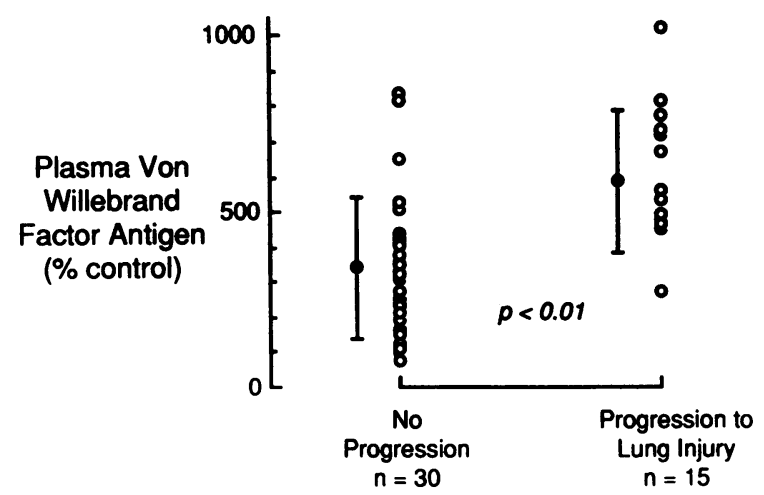

Figure 2. The individual data points represent the plasma von Willebrand factor antigen level (percentage of control) measured at the time of entry into the study. The 30 patients who did not develop lung injury comprise group I and the 15 patients who developed lung injury represent group II. 
Table VI. Value of Plasma von Willebrand Factor Antigen Level $>450$ for Predicting the Development of Acute Lung Injury in Nonpulmonary Sepsis

\begin{tabular}{ccc}
\hline & \multicolumn{2}{c}{$\begin{array}{c}\text { Plasma von Willebrand } \\
\text { factor antigen level* }\end{array}$} \\
\cline { 2 - 3 } Patient classification & $<450$ & $>450^{\ddagger}$ \\
\hline Group I: no progression $(n=30)$ & 23 & 7 \\
Group II: progression to lung & (True negative) & (False positive) \\
injury $(n=15)$ & 2 & 13 \\
& (False negative) & (True positive)
\end{tabular}

* Plasma von Willebrand factor antigen levels are expressed as percent of control.

${ }^{\ddagger} P<0.0005$ by $\chi^{2}$ analysis with Yates correction.

already shown that vWf-Ag levels are elevated in the plasma once acute respiratory failure occurs (9), and we confirmed this finding in our preliminary study (11). Furthermore, once lung involvement is present, the value of an elevated plasma marker is diminished considerably.

The contribution of sepsis to multiorgan failure, lung injury, and a poor outcome has been well documented in a number of studies of medical and surgical patients $(22-25)$. However, the data in this study provide a new perspective on this issue because the entry criteria required the absence of lung injury in patients with sepsis syndrome. Therefore, we were able to evaluate the relationship of nonpulmonary organ failure in septic patients to both the subsequent development of lung injury as well as to mortality. Overall, 29 of the 45 patients in both groups had one or more nonpulmonary organs failing at the time of entry into the study (Table III). Of the 29 patients with nonpulmonary organ failure, 14 developed lung injury (group II) and 15 did not develop lung injury (group I). Of the 14 patients in group II who had nonpulmonary organ failure and progressed to develop lung injury, all 14 died. Thus, there were no survivors among the patients who had one or more nonpulmonary organs failing at the time sepsis syndrome was diagnosed and subsequently developed lung injury. In contrast, 7 of the 15 patients with nonpulmonary organ failure and no progression to lung injury did survive. Thus, these results emphasize the importance of respiratory failure as an additional adverse prognostic factor when it occurs in the setting of nonpulmonary organ failure.

The incidence of chronic diseases was similar in patients in groups I and II. Also, the incidence of positive blood cultures and the frequency of gram-negative infection was the same in the two groups. However, the group II patients had a signifcantly lower arterial $\mathrm{pH}$, a lower diastolic blood pressure, and a higher plasma vWf-Ag level, all of which suggested more severe systemic injury from sepsis. Although the arterial $\mathrm{pH}$ and the diastolic blood pressure were lower in group II patients, these indices did not predict lung injury or mortality because of the overlap in the individual data points. However, the one index that reliably predicted acute lung injury and mortality was a plasma vWf-Ag $>450$ (\% of control) (Table VI).

The possible use of plasma vWf-Ag as a marker of vascular endothelial cell injury is reasonable because vWf- $\mathrm{Ag}$ is synthetized predominantly by vascular endothelial cells (6) and, to a lesser degree, by megakaryocytes and platelets (26). In vitro,
vWf-Ag is used as a specific identifying biochemical marker of vascular endothelial cells (5), and it can be released before the cells are destroyed $(7,8)$. Most of the acute elevation of plasma $\mathrm{vWf}-\mathrm{Ag}$ probably represents a release from stored granules rather than from a stimulation of synthesis. Because of their vast number, it is likely that vascular endothelial cells are the major source of plasma vWf-Ag under physiological and most pathological conditions, including the sepsis syndrome. Although the mechanisms that induce release of endothelial vWf-Ag are unknown, it is conceivable that during sepsis and inflammation the endothelium is exposed to increased levels of histamine, thrombin, and the deposition of fibrin. These events are known to induce release of $\mathrm{vWf}-\mathrm{Ag}$ by cultured endothelial cells and have been linked to an elevation of cytosolic free-calcium $(7,8,27)$.

Elevated plasma vWf-Ag has been used to monitor vascular involvement in a variety of medical diseases. Plasma vWf$\mathrm{Ag}$ is elevated in the vasculitides of rheumatological diseases (28), and is useful in monitoring the degree of vascular involvement (29) as well as the response to therapy (30). Also, other conditions characterized by vascular damage, including primary pulmonary hypertension (31), nephritis (32), myocardial infarction (33), and diabetic angiopathy (34), are associated with elevated plasma levels of vWf-Ag. With the exception of two patients with diabetes mellitus, these illnesses were not present in any of our patients and should not complicate interpretation of the results.

It is difficult to ascertain whether platelet activation contributed to the elevated plasma vWf-Ag; it has been shown that platelet activation may also lead to elevated plasma vWf-Ag (35). Evidence for platelet activation in patients with acute lung injury is found biochemically by documenting contact system proteolysis of thrombi (36) and histologically by noting pulmonary microvascular thrombi (37). There was no relationship between platelet levels and the plasma vWf-Ag in the group II patients. In fact, in the group II patients, the platelet count ranged from 30,000 to 301,000 cells $/ \mathrm{mm}^{3}$ with a mean value $132,286 \pm 96,061$. Yet, 6 of the 15 patients in group II had platelet counts below 75,000 cells $/ \mathrm{mm}^{3}$. Their thrombocytopenia, a gross measure of platelet activation, implies that the platelets could have contributed to the elevated plasma levels of vWf-Ag. Nevertheless, the hypothesis that endothelial pertubation is a major source of high vWf- $\mathrm{Ag}$ levels should still be valid since platelet activation is most likely to occur in the setting of endothelial dysfunction.

At the beginning of this study, we reasoned that an elevated level of plasma vWf-Ag could be reliably detected by obtaining only one plasma sample early in the course of sepsis because the half-life of vWf-Ag had been shown to be $13 \mathrm{~h}$ in patients with von Willebrand disease (38). Also, the results of a recent study showed that plasma vWf-Ag increased three hours after the intravenous administration of endotoxin to normal subjects and remained elevated at $24 \mathrm{~h} \mathrm{(21).} \mathrm{However,} \mathrm{factors} \mathrm{that}$ affect the half-life of vWf-Ag in plasma have not been well studied. Therefore, it is uncertain whether liver disease and other organ failure alter the metabolism of the glycoprotein. We did not find any relationship between liver failure and the level of plasma vWf-Ag in this study.

Finally, do the significantly elevated plasma vWf-Ag levels provide a new and useful predictor of acute lung injury in patients with non-pulmonary sepsis syndrome? Using a plasma vWf-Ag level above 450 , the sensitivity of $87 \%$ is ex- 
cellent and the specificity of $77 \%$ is good. 13 of the 15 patients in group II had plasma vWf-Ag levels above 450 but so did 7 of the 30 patients in group I who did not develop lung injury. Thus, the false-positive rate was $22 \%$, which reduced the overall predictive value of a plasma vWf-Ag $>450$ alone to $65 \%$. Adding diastolic blood pressure or arterial $\mathrm{pH}$ for the prediction equation did not provide a more reliable index than plasma vWf-Ag levels alone. However, if the presence of one nonpulmonary organ failure was added to the requirement for a plasma vWf-Ag $>450$, then the positive predictive value for lung injury in the setting of nonpulmonary sepsis increased to $80 \%$. This combination of abnormalities would be useful for selecting patients for trials of therapeutic interventions designed to prevent or attenuate the development of acute lung injury in patients with nonpulmonary sepsis syndrome.

There are some limiting factors in using plasma vWf-Ag levels to predict lung injury in patients with nonpulmonary sepsis syndrome that should be pointed out. First, as we reported in a recent study (39), $\sim 25 \%$ of patients already have evidence of lung injury at the time sepsis is diagnosed. Secondly, by definition, we have excluded patients who developed sepsis and lung injury from a primary pulmonary source. Thirdly, there may be fragments of vWf-Ag present in septic patients that are not measured by this assay $(15,16)$, but this possibility does not alter the predictive value of this assay. Fourthly, the current rocket immunoelectrophoresis method for assay of the vWf-Ag plasma level is an overnight assay. However, a more rapid ELISA assay has been developed that may be useful clinically (40).

In summary, in patients with nonpulmonary sepsis, the plasma vWf-Ag level was significantly elevated in the 15 patients who progressed to develop lung injury $(588 \pm 204$ vs. $338 \pm 196$, percentage of control, $P<0.01)$. An elevated level of plasma vWf-Ag was $87 \%$ sensitive and $77 \%$ specific for identifying patients with nonpulmonary sepsis who were destined to develop acute lung injury. Although there were $22 \%$ false positive results, the data indicate that elevated plasma vWf-Ag levels are superior to any other presently known plasma marker as a predictor of acute lung injury. Also, if the combination of both a plasma vWf-Ag $>450$ and failure of at least one nonpulmonary organ was used, then the positive predictive value for the development of lung injury increased to $80 \%$. Moreover, the results of this study identified a group of patients with nonpulmonary sepsis syndrome who had a $100 \%$ mortality if they had failure of one or more organs other than the lungs early on in their clinical course, and then subsequently progressed to develop acute lung injury.

\section{Acknowledgments}

The authors thank Elizabeth A. Drab and Helga Kohl for their technical assistance, Dr. Julian Hoffman for his assistance with biostatistical analysis, and Cheryl von Kugler and Sanja Djukic for their help in preparing the manuscript.

This work was supported by a Pulmonary Vascular SCOR grant (HL-19155) and a grant (HL-41155-02) from the National, Heart, Lung and Blood Institute.

\section{References}

1. Harlan, J. M., L. A. Harker, M. A. Reidy, C. Gajdusek, S. Schwartz, and G. Striker. 1983. Lipopolysaccharide-mediated bovine endothelial cell injury in vitro. Lab. Invest. 48:269-274.
2. Meyrick, B., U. S. Ryan, and K. L. Brigham. 1986. Direct effects of $E$. coli endotoxin on structure and permeability of pulmonary endothelial monolayers and the endothelial layers of intimal explants. Am. J. Pathol. 122:140-151.

3. Brigham, K. L., W. C. Woolvertson, L. H. Blake, and N. C. Staub. 1974. Increased sheep lung vascular permeability caused by Pseudomonas bacteremia. J. Clin. Invest. 54:792-804.

4. Brigham, K. L., R. E. Bowers, and J. Haynes. 1979. Increased sheep lung vascular permeability caused by Escherichia coli endotoxin. Circ. Res. 45:292-297.

5. Jaffe, E. A., R. L. Nachman, C. G. Becker, and R. C. Minic. 1973. Culture of human endothelial cells derived from umbilical veins: identification by morphologic and immunologic criteria. J. Clin. Invest. 52:2745-2756.

6. Bloom, A. L., J. C. Giddings, and C. J. Wilks. 1973. Factor VIII on the vascular intima: possible importance in haemostasis and thrombosis. Nature (Lond.). 241:217-219.

7. Hamilton, K. K., P. J. Sims. 1987. Changes in Cytosolic Ca2+ associated with von Willebrand factor release in human endothelial cells exposed to histamine. J. Clin. Invest. 79:600-608.

8. Ribes, J. A., C. W. Francis, and D. D. Wagner. 1987. Fibrin induces release of von Willebrand factor from endothelial cells. J. Clin. Invest. 79:117-123.

9. Carvalho, A. C. A., S. M. Bellman, V. J. Saullo, D. Quinn, W. M. Zapol. 1982. Altered factor VIII in acute respiratory failure. $N$. Engl. $J$. Med. 307:1113-1119.

10. Mazzone, D., A. Fichera, G. Pratico, and F. Sciacca. 1984. Factor VIII activity and von Willebrand factor in infants with viral bronchiolitis. N. Engl. J. Med. 311:1257-1258.

11. Rubin, D. B., M. A. Matthay, P. F. Weinberg, and J. F. Murray. 1985. Factor VIII antigen: possible plasma marker of progressive acute lung injury in patients with sepsis. Am. Rev. Respir. Dis. 131:A142. (Abstr.)

12. Weinberg, P. F., M. A. Matthay, R. O. Webster, K. V. Roskos, I. M. Goldstein, and J. F. Murray. 1984. Biologically active products of complement and acute lung injury in patients with the sepsis syndrome. Am. Rev. Respir. Dis. 130:791-796.

13. Murray, J. F., M. A. Matthay, J. M. Luce, and M. R. Flick. 1988. An expanded definition of the adult respiratory distress syndrome. Am. Rev. Respir. Dis. 138:720-723.

14. Gilbert, R., and J. F. Keighley. 1974. The arterial/alveolar oxygen tension ratio: an index of gas exchange applicable to varying inspired oxygen concentrations. Am. Rev. Respir. Dis. 109:142-145.

15. Laurell, C. B. 1965. Antigen antibody crossed electrophoresis. Ann. Biochem. 10:358-361.

16. Zimmerman, T. S., L. W. Hoyer, L. Dickson, and T. S. Edgington. 1975. Determination of the von Willebrand's disease antigen (factor VIII-related antigen) in plasma by quantitative immunoelectrophoresis. J. Lab. Clin. Med. 86:152-159.

17. Zar, J. H. 1974. Biostatistical Analysis. Prentice-Hall, Inc., Englewood Cliffs, NJ.

18. Pepe, P. E., R. T. Potkin, D. H. Reus, L. D. Hudson, and C. J. Carrico. 1982. Clinical predictors of the adult respiratory distress syndrome. Am. J. Surg. 144:124-130.

19. Fowler, A. A., R. F. Hammen, J. T. Good, B. Benson, B. Baird, D. Eberke, T. L. Petty, and T. M. Hyers. 1983. Adult respiratory distress syndrome: risk with common predisposition. Ann. Intern. Med. 98:593-597.

20. Rinaldo, J. E. 1986. Indicators of risk, course, and prognosis in adult respiratory distress syndrome. Am. Rev. Respir. Dis. 133:343.

21. Suffredini, A. F., P. C. Harpel, and J. E. Parillo. 1989. Promotion and subsequent inhibition of plasminogen activation after administration of intravenous endotoxin to normal subjects. N. Engl. J. Med. 320:1165-1172.

22. Bell, R. C., J. J. Coalson, J. D. Smith, and W. G. Johanson. 1983. Multiple organ system failure and infection in adult respiratory distress syndrome. Ann. Intern. Med. 99:293-298.

23. Fry, P. E., L. Pearlstein, R. L. Fulton, and H. C. JR. Polk. 1980. 
Multiple system organ failure: the role of uncontrolled infection. Arch. Surg. 115:136-140.

24. Montgomery, A. B., M. A. Stager, C. J. Carrico, and L. D. Hudson. 1985. Causes of mortality in patients with the adult respiratory distress syndrome. Am. Rev. Respir. Dis. 132:485-489.

25. Fowler, A. A., R. F. Hamman, G. O. Zerbe, K. N. Benson, and T. M. Hyers. 1985. Adult respiratory distress syndrome: prognosis after onset. Am. Rev. Respir. Dis. 132:472-478.

26. Sporn, L. A., S. I. Chavin, V. J. Marder, and D. D. Wagner. 1985. Biosynthesis of von Willebrand protein by human megakaryocytes. J. Clin. Invest. 76:1102-1106.

27. Levine, J. D., J. M. Harlan, L. A. Harker, M. L. Joseph, and R. B. Counts. 1982. Thrombin-mediated release of factor VIII antigen from human umbilical vein endothelial cells in culture. Blood. 60:531-534.

28. Kahalah, M. B., I. Osborn, and E. C. LeRoy. 1981. Increased factor VIII/von Willebrand factor-antigen and von Willebrand factor activity in scleroderma and in Raynaud's phenomenon. Ann. Intern. Med. 94:482-484.

29. Woolf, A. D., G. Wakerley, T. B. Wallington, D. G. I. Scott, and P. A. Dieppe. 1987. Factor VIII-related antigen in the assessment of vasculitis. Ann. Rheum. Dis. 46:441-447.

30. Belch, J. J. F., A. A. Zoma, I. M. Richards, K. McLaughlin, C. D. Forbes, and R. A. Sturrock. 1987. Vascular damage and factorVIII-related antigen in rheumatic diseases. Rheumatol. Int. 7:107-111.

31. Geggel, R. L., A. C. A. Carvalho, L. W. Hoyer, and L. M. Reid. 1987. von Willebrand Factor abnormalities in primary pulmonary hypertension. Am. Rev. Respir. Dis. 135:294-299.

32. Ambruoso, D. R., D. P. Duranton, R. M. McIntosh, and W. E. Hathaway. 1977. Factor VIII and renal disease. Ann. Intern. Med. 87:636-637.
33. Giustolisi, R., R. Musso, E. Cacciola, R. R. Cacciola, M. Russo, and A. Petralito. 1984. Abnormal plasma levels of factor VIII/von Willebrand factor complex in myocardial infarction-expression of acute phase reaction or index of vascular endothelium damage? Thromb. Haemostasis. 51:408.

34. Lufkin, E. G., D. N. Fass, W. M. O'Fallon, and E. J. W. Bowie. 1979. Increased von Willebrand factor in diabetes mellitus. Metab. Clin. Exp. 28:63-66.

35. Rossi, E. C., D. Green, J. S. Rosen, S. M. Spies, and J. S. T. Jao. 1980. Sequential changes in factor VIII and platelets preceding deep vein thrombosis in patients with spinal cord injury. Br. J. Haematol. 45:143-151.

36. Carvalho, A. C., S. DeMarinis, C. F. Scott, L. D. Silver, A. H. Schmaier, and R. W. Colman. 1988. Activation of the contact system of plasma proteolysis in the adult respiratory distress syndrome. $J$. Lab. Clin. Med. 112:270-7.

37. Tomashefski, J. F., P. Davies, C. Boggis, R. Greene, W. M. Zapol, and L. M. Reid. 1983. The pulmonary vascular lesions of the adult respiratory distress syndrome. Am. J. Pathol. 112:112-126.

38. Over, J., J. J. Sixma, B. N. Bouma, P. A. Bolhuis, R. A. A. Vlooswijk, and N. H. Besser-Visser. 1981. Survival of iodine-125-labeled factor VIII in patients with von Willebrand's disease. $J$. Lab. Clin. Med. 97:332-344.

39. Luce, J. M., A. B. Montgomery, J. D. Marks, J. Turner, C. A. Metz, and J. F. Murray. 1988. Ineffectiveness of high dose methylprednisolone in preventing parenchymal lung injury and improving mortality in patients with septic shock. Am. Rev. Respir. Dis. 138:6268.

40. Cejka, J. 1982. Enzyme immunoassay for factor VIII-related antigen. Clin. Chem. 28:1356-1358. 